\title{
IDENTIFICACIONES SOCIALES Y CONSTRUCCIÓN DE SENTIDOS ÉtNicos entre nahuas urbanos en la CiUdAd de MÉXico
}

\section{Social IDENTIfications And Construction of Etnhic Senses among Urban Nahuas in Mexico City}

\author{
Olivia Leal Sorcia* \\ doi: https://doi.org/10.31644/ED.V8.N2.2021.A01
}

\begin{abstract}
Resumen: A partir de la descripción etnográfica de un grupo de indígenas nahuas que venden revistas en la ciudad de México, me propongo discutir dos categorías de análisis: identificaciones sociales y sentidos étnicos. Busco abonar a una discusión más amplia sobre la emergencia de una etnicidad urbana donde la agencia de los sujetos indígenas es moldeada por sus trayectorias individuales y colectivas en los ámbitos de lucha social, gremial y de demanda de derechos ciudadanos. Su análisis también me permitirá problematizar las tensiones entre los intereses individuales/familiares y los colectivos que se derivan de la sociabilidad cotidiana y que han sido poco explorados en los estudios sobre etnicidades urbanas en México.
\end{abstract}

Palabras clave: agencia y sujetos indígenas, luchas sociales y gremiales de indígenas urbanos, derechos ciudadanos y sentidos étnicos.

\begin{abstract}
Based on the ethnographic description of a group of Nahua speaking indigenous people who sell magazines in Mexico City, the article aims to discuss two categories of analysis: social identifications and ethnic sense in order to contribute to a broader discussion on the emergence of an urban ethnicity in which agency of indigenous subjects is shaped by individual and collective trajectories in social and union struggles, as well as in claims for citizen rights. The analysis will also allow me to problematize the tensions between individual/family and collective interests that stem from everyday sociability, relatively unexplored on studies of urban ethnicities in Mexico.
\end{abstract}

Keywords: agency and indigenous subjects, social and union struggles of urban indigenous, citizen rights and ethnic senses.

\footnotetext{
* Dra. en Ciencias Sociales, profesora investigadora en la Universidad Autónoma de la Ciudad de México, México. ORCiD: http://orcid.org/0000-0001-9146-7682 Correo-e: olivia.leal@uacm.edu.mx; olivia.lealsorcia@gmail.com.

Fecha de recepción: 13/12/2020. Fecha de aceptación: 13/05/2021. Fecha de publicación: 30/07/2021.

\section{(c)) BY-NC-ND}

EntreDiversidades. Revista de Ciencias Sociales y Humanidades, Vol. 8, Núm. 2 (17), julio-diciembre 2021. Páginas: 6-29 ISSN-e: 2007-7610. https://doi.org/10.31644/ED.V8.N2.2021.A01 


\section{Introducción}

Los estudios sobre indígenas urbanos en México experimentan en el cambio de milenio un enriquecimiento notable, tanto en las propuestas de categorías de análisis como en las descripciones etnográficas en torno a grupos escasamente documentados y ciudades que no se circunscriben a las zonas metropolitanas tradicionalmente estudiadas. Sin duda, el cruce de campos de investigación ha contribuido a dicho enriquecimiento. Por ejemplo, las aportaciones de los estudios urbanos, tanto antropológicos como sociológicos, incluyendo la geografía y el urbanismo, han contribuido a poner en el eje de discusión aspectos como la sociabilidad urbana y las territorializaciones y disputas de los espacios urbanos, en tanto corolario central para el entendimiento de los procesos de reproducción cotidiana de los colectivos indígenas en los centros urbanos mexicanos. A esto se suman, desde la ciencia política, la identificación de reformas constitucionales locales y de administración pública que den cuenta de la atención en la dotación de infraestructura y servicios a los asentamientos congregados y dispersos donde habitan las poblaciones indígenas, así como del tipo de programas sociales, y en general acciones de política pública dirigidos a este sector de la población. Asimismo, ha dado pie a la emergencia de demandas por el reconocimiento de derechos políticos y socioculturales. Por su parte, los estudios socioantropológicos han avanzado en temas más contemporáneos como el trabajo, el consumo, el ocio, la inserción ocupacional y escolar o la vida festiva, mientras que los estudios de género han visibilizado la presencia de las mujeres indígenas en diversos campos laborales y sociales en las ciudades (Peña, 2010; Durin, 2010; Hiernaux, 2000; Sánchez, 2014; Pérez Ruiz 2008).

Lo anterior también explica que temas como los procesos migratorios y los cambios y continuidades en las identidades étnicas y genéricas de las mujeres en los espacios urbanos - o bien los procesos de integración, pérdida de la lengua, cambio generacional e inserción en espacios educativos - predominaran en las investigaciones sobre migrantes indígenas a las ciudades a lo largo de las décadas de los años ochenta y noventa del siglo XX, y empezaran a complejizarse y diversificarse durante toda la primera década del dos mil. En adelante, ciudadanía y reconocimiento de derechos políticos, sociales y lingüísticos, inserción ocupacional, sociabilidad urbana y etnicidad, jóvenes indígenas urbanos, consumo, ocio y deporte, visibilización de indígenas en periferias, disputas por los espacios urbanos, entre otros, emergen abarcando diversos grupos y ciudades del país. Esto, sin duda, ha favorecido enfoques dinámicos sobre el entendimiento de las múltiples formas de reproducción sociocultural de los indígenas asentados y radicados mayoritariamente en las urbes mexicanas (Gutiérrez, 2013; Gissi, 2009; Pérez Téllez, 2019).

Las posibilidades de cruce disciplinar también han favorecido el acuñar categorías de análisis o, en todo caso, retomar conceptos desde la teoría social, con el fin de explicar fenómenos contemporáneos de la cotidianidad indígena en los centros urbanos. De manera un tanto esquemática, podría referir a modo de ejemplo, varias de ellas. Empiezo con "etnicidad urbana", la cual viene a suplir en varios estudios la de "migrante indígena", y cuyo sentido refiere a que en los escenarios urbanos multiétnicos no hay formas unívocas de ser indígena, de reconocerse como miembro de una minoría cultural, o de reivindicarse o negociar su presencia en las ciudades (Zárate y Leal, 2018). "Resignificación cultural” y "reconocimiento étnico" son otras categorías que se proponen para complejizar los análisis de corte esencialista propuestos desde el concepto

EntreDiversidades. Revista de Ciencias Sociales y Humanidades, Vol. 8, Núm. 2 (17), julio-diciembre 2021. Páginas: 6-29 ISSN-e: 2007-7610. https://doi.org/10.31644/ED.V8.N2.2021.A01 
de identidad indígena. "Referencias a la gestión social” y "agencia de sujetos étnicos" cobra importancia para superar los enfoques de la asimilación e integración estructural de los indígenas a las ciudades, con el propósito de identificar nuevos significados a partir de las experiencias laborales y familiares, pero sobre todo, de demandas de derechos ciudadanos (Martínez, 2007; Morales, 2018; Herrera, 2018; Vázquez y Prieto, 2013; Rodríguez, 2019).

En síntesis, las nuevas orientaciones en los estudios sobre indígenas urbanos parten de reconocer las formas plurales de reivindicar el origen, pero, a su vez, ponderan los vínculos significativos construidos con lo urbano e incluso avanzan en adentrarse y, por ende, etnografiar, las experiencias cotidianas de los sujetos indígenas en torno a los aspectos estéticos de los barrios donde habitan y trabajan, los lazos afectivos que crean y recrean con los suyos y los otros no indígenas, incluyendo diversas esferas de lo institucional, además de visibilizar la inequidad, violencia y desigualdad que enfrentan también de manera cotidiana, identificando actos situacionales específicos (Chávez, 2013; Leal, 2019; Oehmichen, 2010; Yanes, 2010).

Para los propósitos del presente escrito, y tomando como referente estas nuevas miradas en torno a los estudios sobre indígenas urbanos, analizo un espacio de encuentro gremial y grupal de indígenas de origen nahua en la ciudad de México. Se trata de una asociación de vendedores de revistas atrasadas. Su consolidación como espacio de trabajo se fundamenta en la puesta en marcha de valores y formas de colaboración sustentadas desde su diferenciación étnica, pero también en otras justificaciones discursivas que trascienden lo étnico y se ubican en el terreno de los derechos laborales, como se verá en la narración del caso. Así, la descripción de la Asociación de revistas me permitirá recuperar las nociones que diversos actores y grupos han configurado en torno al trabajo grupal y colaborativo que observan por parte de familias y sujetos de origen nahua autodenominados "chilas", ${ }^{1}$ resaltando un juego de espejos entre los "otros" no chilas y los chilas.

Por otro lado, narraré la configuración de sus propios procesos de adscripción identitaria y de su pertenencia a espacios y grupos donde han venido reinventando su ser chila en el marco de un contexto metropolitano. En algunos momentos pueden hacer referencia al origen étnico: lo nahua y el pueblo de origen en Chilacachapa Guerrero, incluso desde un tinte instrumental, mientras que en otros momentos, generan fuertes reivindicaciones en el marco de una demanda de pertenencia a lo local, la ciudad de México, y/o lo global, resaltando el ser mexicanos y ciudadanos.

Con respecto al enfoque metodológico, destaco que mi acercamiento con los chilas con fines de investigación suma ya una década e inició con el fin de desarrollar mi tesis doctoral (Leal, 2014). El espacio urbano donde principalmente registré información etnográfica corresponde a una colonia ubicada al extremo norte de la ciudad de México, en la que documenté las dinámicas y formas de socializar de distintos sujetos y familias de origen nahua durante el periodo 2011-2014. Mis registros los realicé en lo que llamo "tiempo real", es decir, observé sus formas de participación social en diversos espacios de interacción, tales como una casa de cultura, un comité vecinal muy activo en esos años, además de una asociación civil, la cual

${ }^{1}$ Chila es el diminutivo de Chilacachapa, nombre del pueblo del cual son originarios, ubicado en la región norte del estado de Guerrero. Dicho término es común entre paisanos, así como entre otros grupos, quienes también los nombran así.

EntreDiversidades. Revista de Ciencias Sociales y Humanidades, Vol. 8, Núm. 2 (17), julio-diciembre 2021. Páginas: 6-29 ISSN-e: 2007-7610. https://doi.org/10.31644/ED.V8.N2.2021.A01 
agrupa vendedores de revistas y libros que se instalan en puestos de periódicos en diversas calles y avenidas de la ciudad de México. ${ }^{2}$ Durante el periodo 2015-2018 mi seguimiento hacia dichos espacios de participación ha sido más discontinuo, no obstante he podido identificar cambios en sus formas de interacción cotidianas, permitiendo así, reconstruir y diferenciar históricamente sus distintas etapas de funcionamiento.

A partir de entrevistas extensas a gestores, líderes, comerciantes, músicos tanto hombres como mujeres que se reconocen como chilas, empecé a advertir cómo ciertos sujetos (hombres y mujeres) participaron (y algunos lo siguen haciendo) al mismo tiempo en dos o más espacios que ya se mencionaron; o bien se involucraban de forma activa primero en uno y posteriormente asumieron cargos en otro, generando cruces en sus formas de participación de forma ascendente o viceversa, o bien de forma escalonada en los diferentes cargos y puestos, dependiendo el tipo de organización.

Lo anterior ejemplifica un empalme permanente entre las formas de organización, representación y adscripción por parte de los chilas a lo largo de casi tres décadas de vivir en la ciudad de México, una veces alimentadas desde el terruño de las colonias donde radican y en diversas ocasiones en sintonía con otros intereses y demandas de paisanos radicados en diferentes puntos del valle de México, accediendo a diferentes nichos ocupacionales. ${ }^{3}$

Para desarrollar lo expuesto anteriormente, el presente escrito lo divido en tres apartados. En el primero expongo de forma general características socioculturales de los chilas, mismas que enlazo en un primer momento con las propuestas analíticas de los conceptos: identificaciones sociales y sentidos étnicos. En un segundo apartado explico la historia del surgimiento de la Asociación de revistas, destacando sus cruces con la emergencia de otras formas de organización colectiva entre los chilas, así como los mecanismos de formación política que han impulsado para consolidar este nicho laboral en la ciudad de México. Aquí incluyo de nueva cuenta la categoría de identificaciones sociales, precisamente para evidenciar los diversos niveles de reconocimiento impulsados por los chilas desde su asentamiento definitivo en la ciudad de México. Ya en el tercer apartado se destacan testimonios de algunos integrantes de la Asociación, quienes han asumido algunos cargos, con el fin de articular la propuesta de sentidos étnicos, donde resalto las trayectorias individuales con la manifestación de afectos y solidaridades hacia el colectivo étnico de los chilas.

\footnotetext{
${ }^{2}$ Tanto la casa de cultura como el comité vecinal se asientan en la colonia Vista Hermosa, ubicada en Cuautepec, en el extremo norte de la ciudad de México.

${ }^{3}$ Los chilas mantienen un patrón de residencia disperso en diferentes puntos de la Zona Metropolitana del Valle de México. No obstante, se ubican conjuntos numerosos de familias en ciertas zonas donde sus viviendas pueden o no presentar contigüidad. Destacan para la Ciudad de México las siguientes colonias: Santo Domingo (alcaldía Coyoacán), Xalpa (Iztapalapa), Pensil (Miguel Hidalgo) y Vista Hermosa (Gustavo A. Madero); y para el Estado de México los municipios de Ecapetec y Tlalnepantla de Baz.
}

EntreDiversidades. Revista de Ciencias Sociales y Humanidades, Vol. 8, Núm. 2 (17), julio-diciembre 2021. Páginas: 6-29 ISSN-e: 2007-7610. https://doi.org/10.31644/ED.V8.N2.2021.A01 


\section{Apuntes sobre identificaciones sociales y la emergencia de sentidos étnicos}

Las historias diversas sobre los procesos de asentamiento de los chilas en distintas colonias de la capital del país, y también en ciertos municipios de la Zona Metropolitana del Valle de México (ZMVM), sin duda son similares a las de otros grupos indígenas que arribaron a la gran metrópoli mexicana, principalmente desde las décadas de los setenta y ochenta del siglo XX. Por lo regular, primero se desplazaron hombres solos hacia las zonas céntricas de la ciudad y posteriormente arribaron las familias, en condiciones precarias, con nula o baja escolarización, y con incipientes contactos que facilitaran el asentamiento y la incorporación al mercado de trabajo formal.

No obstante, el caso de los chilas, sigue el patrón de otros grupos también de origen nahua oriundos de los estados de Guerrero y de Veracruz, cuyas formas de organización sociopolítica les permitieron diversificar tanto las estrategias de acceso al suelo urbano (desplazándose a las periferias desde la misma década de los ochenta) como a la incorporación a empleos informales, pero que no se agotaron en la construcción ni en el trabajo doméstico como se ha documentado para otros grupos indígenas provenientes sobre todo de los estados del centro del país. Esta distribución temprana en las periferias para ese momento en proceso de consolidación urbana, por ejemplo, les permitió acceder a solares, siendo la autoconstrucción el principal mecanismo para edificar viviendas de su propiedad. A pesar de que no todas las familias pudieron adquirir un predio, quienes sí lo hicieron, sin duda, pudieron establecerse de forma definitiva en la ciudad de México. Además, esto permitió desplegar una gama de recursos para el acceso a empleos tanto formales como informales, siempre bajo el cobijo de redes muy tempranamente consolidadas, donde el paisanazgo en primer lugar, pero también el compadrazgo, jugaron y siguen jugando un papel central en la continuidad y fuerza de sus procesos organizativos colectivos (Díaz, 2015; Leal, 2014).

Sobre los chilas en particular, varios estudios han dado cuenta de sus patrones de migración, pero específicamente han descrito en detalle sus procesos de formación en la gestión social y de formación política como uno de sus rasgos étnicos más sobresalientes (Ruiz, Pineda y Luna, 2019; Leal, 2015). Más que su vida festiva o sus particularidades en la reproducción de ciertas redes de apoyo, las investigaciones han destacado sus interacciones cotidianas en los espacios urbanos, bajo lógicas de disputa y competencia por recursos públicos y de programas sociales. Lo anterior habla de la presencia visible de los chilas en ciertos contextos urbanos, lo cual deriva en la emergencia permanente de liderazgos — que se hacen presentes en las luchas vecinales para el mejoramiento de sus asentamientos-, pasando por el financiamiento de pequeños talleres de maquila o puestos de comida y de venta ambulante, hasta la demanda de espacios de encuentro paisanal en la ciudad y el interés en el funcionamiento de cierto tipo de asociaciones civiles.

En cuanto a la visibilidad, conviene precisar que se trata de un colectivo que no reproduce ya la lengua náhuatl ni porta ningún elemento tradicional como la vestimenta o tipo de viviendas, sino que es a partir de eventos públicos (y de su presencia en espacios urbanos de distinta índole) cuando en sus discursos permanentemente destacan su origen nahua, sus formas comunitarias de organización, sus vínculos afectivos con los paisanos y parientes y, en general, con el uso por ejemplo de calles, patios y aceras para reproducir fiestas del ciclo de vida, donde confluyen numerosas familias dispersas por la ZMVM. Asimismo, recurrentemente ocupan puestos y cargos en diversas organizaciones formales e informales, por lo cual, otros participantes les reconocen

EntreDiversidades. Revista de Ciencias Sociales y Humanidades, Vol. 8, Núm. 2 (17), julio-diciembre 2021. Páginas: 6-29 ISSN-e: 2007-7610. https://doi.org/10.31644/ED.V8.N2.2021.A01 
atributos positivos sobre sus liderazgos. Estos participantes pueden ser paisanos, o bien de otros grupos indígenas y no indígenas, así como funcionarios de diversos niveles de gobierno, y hasta otros actores como servidores públicos, académicos y estudiantes, con quienes mantienen relaciones de diverso tipo.

Por lo descrito y documentado hasta el momento para el caso de los chilas, lo que observo es que al participar de forma simultánea en diversos campos de lucha social han acumulado conocimientos, estrategias e información, mismos que pueden utilizar para beneficiarse de forma individual y/o asumir un compromiso grupal cuyos beneficios se espera alcancen a otro conjunto de familiares o paisanos.

Por otro lado, el caso me permite mostrar la relación que los chilas han construido entre identificaciones sociales y la configuración de lo que llamo sentidos étnicos. Es decir, parto de que la historia de su asentamiento en la ciudad de México ha oscilado entre visibilizar su pertenencia étnica o subsumirla a una condición de clase, dependiendo la coyuntura y/o el ámbito donde se desenvuelven (doméstico, familiar, ocupacional, festivo). En este dinámico oscilamiento de identificaciones (Brubaker y Cooper, 2005; Hall, 2003), la dimensión entre las luchas impulsadas colectivamente o bien de forma individual por parte de los sujetos chilas, posibilita discutir las características de su agencia en actos situacionales o bien en ámbitos específicos sobre todo de su vida cotidiana y trabajo.

Pero, ¿qué caracteriza el dinamismo de su participación en diversos ámbitos de lucha social, vecinal o gremial, así como la maleabilidad que se observa de sus adscripciones étnicas? Para dar respuesta a dichas interrogantes retomo la propuesta conceptual de Brubaker y Cooper (2005). Ambos parten de una fuerte crítica al concepto de identidad, ante lo cual proponen, entre otros, el concepto de identificación. En tono irónico, refieren que el uso del término identidad tiende a significar demasiado, demasiado poco, o nada, dependiendo de la corriente, autor o tipo de problemática a analizar. De ahí que señalen: "la discusión crítica sobre 'identidad' no ha aspirado a desechar, sino a salvar el término mediante su reformulación para inmunizarlo de ciertas objeciones, especialmente de la temible acusación de 'esencialismo"” (2005:189). Como una especie de corolario, apuntan que para ellos el término "identidad" no es indispensable para el análisis de la vida social. ${ }^{4}$ Sin duda, su radical crítica los lleva a plantear lo que llaman "otros términos analíticos alternativos", entre los que mencionan los siguientes: identificación y categorización; autocomprensión y localización social; comunidad, conexidad y grupalidad. Retomo en especial los dos primeros, ya que considero son los que brindan herramientas explicativas para el caso de los chilas.

\footnotetext{
${ }^{4}$ Una propuesta menos radical la señala Stuart Hall, quien considera que el concepto de identidad (junto con otros conceptos acusados de esencialismos) desde una crítica deconstructiva se intentó reemplazar por "otros más verdaderos" o que aspiraran a la construcción de conocimiento: "Pero como no fueron superados dialécticamente y no hay otros conceptos enteramente diferentes que pueden reemplazarlos, no hay más remedio que seguir pensando en ellos, aunque ahora sus formas se encuentren destotalizadas o deconstruidas y no funcionen ya dentro del paradigma en que se generaron en un principio... La identidad es un concepto de este tipo, que funciona 'bajo borradura' entre el intervalo entre inversión y surgimiento; una idea que no puede pensarse a la vieja usanza, pero sin la cual ciertas cuestiones clave no pueden pensarse en absoluto" (2003:13-14).
}

EntreDiversidades. Revista de Ciencias Sociales y Humanidades, Vol. 8, Núm. 2 (17), julio-diciembre 2021. Páginas: 6-29 ISSN-e: 2007-7610. https://doi.org/10.31644/ED.V8.N2.2021.A01 
Como una referencia que indica un proceso y una actividad, la palabra "identificación" carece de las connotaciones reificantes del término "identidad", puntualizan Brubaker y Cooper, por lo cual, nos invitan a especificar los agentes que llevan a cabo la identificación. Cabe señalar que esto no presupone que tal identificación (aun realizada por los poderosos agentes del Estado) suponga como consecuencia necesaria la semejanza interna, la distinción, la dimensión "grupal" consolidada que pueden intentar crear los líderes políticos. La identificación — de uno mismo y de los otros - es intrínseca a la vida social; la "identidad" en el sentido fuerte no lo es, enfatizan (2005: 192).

Debido a que en las sociedades modernas las interacciones entre los individuos tanto en la vida cotidiana como en contextos más formales u oficiales se multiplican, se puede entender que "la autoidentificación — dicen los autores_ y la identificación del otro son fundamentalmente actos situacionales y contextuales” (2005: 193). Pero ¿cuáles son las esferas desde donde se genera este doble proceso? La primera se refiere al sí mismo, esto es con respecto a la posición que se guarda en una red relacional, y como ejemplos señalan una red de parentesco, de amistad o de relación patrón-cliente por mencionar algunas; aquí podría agregar la de un gremio ocupacional. También puede tratarse de una clase de personas que comparten algún atributo categorial: raza, etnia, lengua, nacionalidad, ciudadanía, sexo u orientación sexual. La segunda esfera alude a la categorización que los otros hacen de uno, y ahí mencionan al Estado moderno como un "poderoso identificador" en tanto dispone "de los recursos materiales y simbólicos para imponer las categorías, los esquemas clasificatorios y los modos de recuento e informe sociales con los que los funcionarios, los jueces, los profesores y los médicos deben trabajar y a los que los actores no estatales deben cumplir” (2005: 194). Aunque, agregan, ningún Estado es tan poderoso para monopolizar este sentido categorizador. De hecho, retoman de la literatura sobre movimientos sociales cómo los líderes desafían las identificaciones sociales y las sustituyen por otras alternativas. Como se observará en el caso de los chilas, y particularmente quienes participan en la Asociación de revistas, históricamente han generado procesos de identificación a partir de los cuales han moldeado su adscripción étnica en un medio urbano.

Lo anterior, lo vinculo con otra dimensión de análisis que comprende aspectos como la empatía, los afectos y relaciones de solidaridad, ayuda y cooperación, que abiertamente los chilas reconocen entre ellos mismos cuando narran acciones que consideran históricas o relevantes, ya sea del pueblo de origen, de su asentamiento en la ciudad de México, de la reproducción de su vida festiva en ambos espacios, o bien, en la participación de comités de lucha e incluso nichos ocupacionales. Son conscientes en sus discursos al señalar a los sujetos, familias o grupos que han impulsado diversas acciones para la obtención de mejoras y beneficios grupales, lo cual ha llegado a cohesionarlos como colectivo étnico. Esto lo explico a partir de lo que Rachel Bloul (1999) llama agentes de etnicidad, a los cuales los vincula a un dominio afectivo desde donde también se alimenta la agentividad de los sujetos. Y es a partir de ponderar dicho dominio afectivo donde conecto la categoría de "sentidos étnicos", la cual defino como aquellos referentes de identificación que los chilas construyen desde sus atribuciones individuales y luchas personales, lo que les permite acumular capital social y político, para desde esta base vincularse con otros sujetos chilas, con otros actores o también con lo institucional. Aspectos que se potencializan en

EntreDiversidades. Revista de Ciencias Sociales y Humanidades, Vol. 8, Núm. 2 (17), julio-diciembre 2021. Páginas: 6-29 ISSN-e: 2007-7610. https://doi.org/10.31644/ED.V8.N2.2021.A01 
los contextos urbanos en los que se desenvuelven, particularmente en la ZMVM, y que permean fuertemente sus formas de sociabilidad, más allá de sus lazos tradicionales de convivencia entre familiares, compadres y paisanos.

El interés por acuñar dicho concepto se debe a la continua expresión de atributos personales que hombres y mujeres chilas mencionan de otros paisanos, compadres y parientes durante eventos públicos como las fiestas del ciclo de vida — altamente recurrentes en la cotidianidad de las familias chilas, tanto en los asentamientos urbanos donde residen como en el pueblo de origen-, además de otros espacios de interacción como las asambleas vecinales, gremiales, o bien reuniones paisanales. Como se resaltará más adelante con la presentación de testimonios de algunos integrantes de la Asociación de revistas, la adscripción a diversos espacios de lucha social y de organización gremial permite ponderar la importancia que juegan sus identificaciones individuales y colectivas sobre su ser chila, pero al mismo tiempo construir emblemas de contraste entre ellos. Esto debido a la heterogeneidad de sus aspiraciones individuales en su devenir social y laboral en la ciudad y su participación en los espacios de la vida comunitaria, donde el compromiso con lo colectivo moldea también su sentido de pertenencia al "ser (indígena) chila". $\mathrm{Al}$ respecto, durante los periodos de trabajo de campo registré frases y situaciones donde los chilas manifestaron un afecto genuino hacia el colectivo, los parientes, el territorio, los oficios, entre otros. Sin embargo, esto no significa la existencia de discrepancias y cuestionamientos sobre el proceder de ciertas figuras, gestores y líderes. Pasemos a continuación a conocer la historia de la Asociación y su papel en la reproducción económica de decenas de familias chilas en la capital del país.

\section{Formación política y diferenciación étnica: el caso de la Unión de Revistas Vicente Guerrero}

El nombre completo de lo que en adelante llamo Asociación de revistas es "Unión de revistas, libros y publicaciones atrasadas Vicente Guerrero Saldaña, A.C.” El analizar este caso adquiere relevancia por varias razones. La primera es que da cuenta de la conformación de un grupo de personas que opera bajo la figura de asociación civil y que defiende los derechos de un gremio ocupacional que ha sido muy importante en la estabilidad económica de muchas familias oriundas de Chilacachapa y también en la integración a las dinámicas urbanas de la capital del país. Nulamente documentado, este espacio de trabajo encabezado por chilas permite, por otro lado, resaltar que las relaciones entre paisanos, familiares, amigos y compadres, hombres y mujeres, encuentran puntos en común más allá de las relaciones ancladas en el parentesco, el compadrazgo y el paisanaje, configurándose otro tipo de relaciones que implican jerarquía, lealtad y compromiso en tanto se vincula con procesos de reproducción económica de la vida diaria. ${ }^{5}$ A continuación, se narra su surgimiento y consolidación.

${ }^{5}$ Existe una ausencia de trabajos que abonen a la caracterización de nichos laborales especializados por parte de
ciertos grupos indígenas en las ciudades mexicanas. Los temas más trabajados corresponden al comercio ambulante
y trabajo doméstico. Como excepciones, se pueden mencionar los trabajos de Nicolás Gissi (2009 y 2012) sobre
chocholtecos dueńos de farmacias en la alcaldía Iztapalapa, ciudad de México; así como el trabajo inédito de Virginia

EntreDiversidades. Revista de Ciencias Sociales y Humanidades, Vol. 8, Núm. 2 (17), julio-diciembre 2021. Páginas: 6-29 ISSN-e: 2007-7610. https://doi.org/10.31644/ED.V8.N2.2021.A01 
Una de las primeras personas en vender revistas atrasadas en cines y avenidas principalmente en el Centro Histórico de la ciudad de México, originaria de Chilacachapa, Guerrero, fue el señor Lino Segura. La época corresponde a principios de los años sesenta del siglo XX. El porqué dedicarse a la venta de revistas atrasadas y no a otros oficios se debió ante todo a la posibilidad de no estar sujeto a un horario fijo y también a que no se requería contar con estudios de nivel medio o superior. Poco a poco, otros paisanos se empezaron a ocupar en este oficio, y con el paso del tiempo decidieron participar en una agrupación formal. Así, se afiliaron a la Unión de Vendedores de la República Mexicana, organización simpatizante del Partido Revolucionario Institucional (PRI). Durante quince años fueron agremiados y desde el interior de la organización y ante la llegada de nuevos paisanos fue constante la denuncia de varias irregularidades que ellos observaban del manejo de la agrupación.

La participación de los oriundos de Chilacachapa en dicha agrupación transcurrió durante mucho tiempo en constantes desencuentros con la dirigencia en turno, por lo cual decidieron escindirse y formaron un grupo disidente. Pero la conformación de una nueva asociación estuvo plagada de conflictos, no solo entre el grupo recién formado y el oficialista, sino entre los mismos paisanos de Chilacachapa. A partir los años noventa empezó un largo periodo de enseńanza y aprendizaje en la conformación de una nueva agrupación donde se aglutinaron principalmente los paisanos pero también otros vendedores de diversos orígenes que estaban en desacuerdo con la agrupación oficial. Si bien la intención era formar una cooperativa, al final crearon una asociación civil. Alberto, uno de los fundadores, comenta que debido a que no contaron con un asesor jurídico que les explicara qué era una asociación civil no imaginaron lo tortuoso que implicaba su gestión. Los primeros meses, por lo tanto, supusieron un aprendizaje continuo en el que contaron con la participación de distintos asesores, algunos paisanos y otros provenientes de diversos lugares y organizaciones.

Un dato relevante es que varios de los chilas que encabezaron la formación de la Asociación de revistas, al mismo tiempo participaban en otros espacios de lucha social, vecinal y/o política. Por lo cual, si bien les demandó un arduo trabajo, por ejemplo en cuanto a desentrañar las formas administrativas para operar como asociación civil, lo cierto es que la parte de la militancia no representó algo nuevo. Será sobre todo hacia fines de la década de los ochenta, y hasta los primeros años de los noventa, que se generó un proceso de gran dinamismo en torno a la participación de los chilas en diferentes espacios organizativos. Esto, además, potencializó la comunicación entre los paisanos, ya que los encuentros e interacciones no se restringieron solo a los planos familiares y de compadrazgo, ya de por sí significativos y estratégicos para lograr una mejor inserción ocupacional y de acceso a vivienda propia en la ciudad de México, sino que en el plano de su participación activa en diversas organizaciones resultaba un asunto público, por lo que conocían quién o quiénes simpatizaban en tal o cual organización, dónde vivían y a qué se dedicaban. Aspectos estratégicos para decidir si se afiliaban o bien militaban en una determinada organización.

Molina (2006). Estudios más recientes versan sobre purépechas y nahuas (carpinteros) (Morán y Ruelas, 2019); sobre profesionistas indígenas en la ciudad de San Luis Potosí (Chávez, 2014) y sobre mazatecos empleados en tiendas de abarrotes en el mercado de la Merced (Zentella, 2015), entre otros.

EntreDiversidades. Revista de Ciencias Sociales y Humanidades, Vol. 8, Núm. 2 (17), julio-diciembre 2021. Páginas: 6-29 ISSN-e: 2007-7610. https://doi.org/10.31644/ED.V8.N2.2021.A01 
Por otro lado, sobre el nombre de la Asociación de revistas resalta el interés de sus fundadores por otorgarle un significado que los identificara como pueblo y que denotara sus características socioculturales. En este sentido, mencionaron lo siguiente:

[...] se crea la agrupación, y se iba a llamar Sociedad Cooperativa, ¡después no! Que se iba a llamar Asociación Macuixóchitl, nombre náhuatl, tratando de recuperar lo náhuatl y la esencia del pueblo, y pues otros decían que en su mayoría somos "los chilas" y pertenecemos al estado de Guerrero, ¿por qué no el héroe nacional que no es tan reconocido, como otros que le dan tanto renombre, que no les corresponde? Entonces ya por votación se da el nombre de Vicente Guerrero Saldaña, y entonces de ahí empieza ya la historia [...] (Leal, 2011: 10, entrevista a Alberto Ortega). ${ }^{6}$

Justo a partir de este tipo de testimonios es que se enriquece notablemente el análisis de la etnicidad para el caso de los chilas. Esto es, de las formas tan flexibles que moldean los contenidos de sus identificaciones sociales y grupales, expresadas abiertamente por ellos mismos. Por ejemplo, de lo que señala Alberto, un primer nivel de identificación se dio con lo que llaman "lo nahua", "la esencia del pueblo", pero finalmente se decide nombrar a la Asociación a partir de un referente más amplio en términos territoriales, donde se pudieran identificar más paisanos. Es decir, se amplía el nivel de pertenencia a nivel estatal. Destaca desde este momento el sentido de apertura que tendrán los chilas para asociarse, separarse y delimitar estrategias que les permitirán potenciar sus formas de trabajo y también moldearán sus interacciones y relaciones de carácter interétnico con otros grupos.

La agrupación de revistas finalmente obtuvo su acta constitutiva el 18 de abril de 1989. Sin embargo, desde ese año y hasta la fecha, su operación ha implicado un trabajo arduo y permanente de sus agremiados y en particular de sus distintos dirigentes y mesas directivas, quienes han aprendido de forma sistemática, diversas esferas de la gestión pública. Desde un inicio, el sostenimiento de los gastos que implicó dar de alta la asociación civil y su posterior manejo siempre fue cubierto por los agremiados (pago para trámites, transportes, comidas y requerimientos generales). La nueva Asociación debía resolver su autofinanciamiento y al mismo tiempo buscar un espacio en donde reunirse y sostener sus juntas con el resto de los integrantes. Este proceso fue tal vez el más tortuoso. Fue así que en la primera oportunidad rentaron el despacho, en el que se sesionan hasta la fecha, localizado en la calle de Tacuba, en el corazón del centro histórico de la Ciudad de México. Ya hacia el inicio de la segunda década del año dos mil, sumaron aproximadamente ciento treinta agremiados. Desde hace un quinquenio expresan reiteradamente que su principal reto es mantener esta fuente de empleo como una opción digna para todos sus agremiados.

\footnotetext{
${ }^{6}$ Los testimonios relatados en este apartado fueron tomados en su mayoría de una extensa entrevista colectiva que realicé a cinco integrantes de la Asociación de revistas en su local gremial ubicado en la calle de Tacuba en el Centro Histórico de la ciudad de México, el día 23 de junio de 2011. Las referencias testimoniales se complementaron con otras entrevistas recopiladas durante trabajo de campo en el periodo 2012-2014. Y, posteriormente, charlas con varios integrantes de la Asociación en sus puestos de revistas (2015-2018).
}

EntreDiversidades. Revista de Ciencias Sociales y Humanidades, Vol. 8, Núm. 2 (17), julio-diciembre 2021. Páginas: 6-29 ISSN-e: 2007-7610. https://doi.org/10.31644/ED.V8.N2.2021.A01 
Las ventajas a resaltar sobre este nicho laboral es que se pueden emplear a varios miembros de la familia, siendo las mujeres y los hijos jóvenes elementos estratégicos para atender los puestos cuando los hombres requieren trasladarse a otros puntos, o bien dedicarse a ciertas tareas de gestión social. Son sus propios patrones y también les permite flexibilizar sus horarios de trabajo. No se requieren estudios mínimos para atender los locales y, por ello, muchos adultos mayores que incluso no saben leer ni escribir están al frente de los puestos de revistas. Asimismo, a algunas familias les permite rotar a sus miembros si se presenta la oportunidad de acceder a otro tipo de empleo. Si se pierde el trabajo, siempre se puede regresar a atender el puesto. Por lo tanto, el contar con un espacio de trabajo de este tipo representa una seguridad para acceder a ingresos monetarios permanentes, aun cuando estos no sean extraordinarios.

Por otro lado, lograr el funcionamiento de la Asociación de revistas ha implicado el impulso de diferentes procesos organizativos. Al principio, el aprendizaje fue intenso y tortuoso. Una década después lograron estabilizar los trabajos del gremio y garantizar su funcionamiento hasta la actualidad. Forman parte del sector de trabajadores no asalariados que los exime de pagar impuestos, pero les obliga a cumplir con diversos requisitos establecidos por diferentes dependencias a nivel local en la Ciudad de México, por ejemplo, las alcaldías políticas y secretarías como Economía, Trabajo, Relaciones Exteriores, entre otras. Cumplir con los requerimientos de operación de la Asociación los ampara para que no sean desalojados de las calles y esquinas donde tienen instalados sus puestos de revistas y para que tampoco sean extorsionados por inspectores de la vía pública. ${ }^{7}$

Para desentrañar el camino de aprendizaje en el manejo de la Asociación, y en general del involucramiento de los chilas en diversos procesos organizativos, en particular en la defensa de la vivienda y del acceso a programas sociales, es necesario periodizar ciertos momentos en su historia de asentamiento y consolidación urbana en distintos vecindarios en la ciudad de México. Destaca de la historia de conformación de la Asociación que los mismos integrantes la vinculen con otros procesos organizativos impulsados por sus paisanos, muchos de ellos familiares. Debido a que en la Asociación confluyen chilas asentados en diversos puntos de la ciudad de México, muchos de ellos emparentados o bien relacionados por lazos de compadrazgo, todos conocen a detalle las luchas sociales sostenidas en diversos periodos, así como las acciones conjuntas emprendidas por hombres y mujeres que han fungido como líderes dependiendo el tipo de problemática. De las entrevistas resalta una memoria colectiva viva donde todos reproducen relatos desde el

\footnotetext{
${ }^{7}$ Un aspecto que no se abordará en este escrito, pero que juega un papel relevante en la continuidad de este nicho laboral, se debe a las peculiaridades del mobiliario urbano que caracteriza a los puestos de periódicos en la Ciudad de México, el cual consiste en una estructura de metal fija modernizada en su diseño en los últimos años. Si bien los puestos de los chilas se centran en la venta de revistas y libros, lo cierto es que también comercializan diversos productos como dulces, artesanías, especialmente canastos y bolsas de palma y rafia sintética, muñecos de peluche de moda, juguetes y durante el periodo de confinamiento cubrebocas con motivos artesanales (que por supuesto, mujeres y hombres chilas maquilan en sus casas). A diferencia de los puestos ambulantes, los puestos de periódicos en la ciudad de México son aceptados en general por los transeúntes, y no se les asigna una connotación negativa. Por otro lado, su ubicación en calles y avenidas transitadas y estratégicas en diversos puntos de la ciudad les garantiza ingresos, si bien, no en grandes volúmenes, sí de forma continua, e incluso han logrado consolidar relaciones comerciales con vecinos, otros vendedores o trabajadores que laboran por las distintas zonas de la ciudad donde se instalan los puestos de periódicos.
}

EntreDiversidades. Revista de Ciencias Sociales y Humanidades, Vol. 8, Núm. 2 (17), julio-diciembre 2021. Páginas: 6-29 ISSN-e: 2007-7610. https://doi.org/10.31644/ED.V8.N2.2021.A01 
asentamiento original y lo que aprendieron de la historia del pueblo, de sus luchas y liderazgos. Pero también reconocen y valoran de forma positiva los apoyos que han obtenido de otros grupos e individuos a lo largo de varias décadas de lucha. Por ejemplo, destacan las solidaridades entre los guerrerenses, no importando la región de origen, pues en la ciudad se configura un sentimiento de pertenencia más general, al igual que sucede con los oaxaqueños o veracruzanos, por mencionar algunos. También han contado con la asesoría de estudiantes universitarios y de líderes de otras agrupaciones sociales y políticas, de quienes han aprendido diversas estrategias de lucha, las cuales han podido potenciar en sus tareas de gestión. Si bien sus experiencias cotidianas de lucha han servido de base para su configuración, lo cierto es que no han recorrido solos y de forma aislada sus procesos organizativos. Podemos decir que es la conjunción de esta doble vía de trabajo lo que les ha permitido ejercer liderazgos en diversos ámbitos de acción.

Chilacachapa es el único pueblo que siempre ha tenido líderes naturales. Para la sociología estos líderes surgen del pueblo y algunos sin ninguna instrucción, ni primaria ni nada; tenemos el caso de Isidro Delgado; no sabía leer el hombre... pero tenía mucha visión... Fue la lucha por la tierra la que lo llevó dar hasta la vida, en el decreto de 1936 cuando Chilacachapa lo ponen como pueblo originario, desde ese momento él entendió que había que recuperar toda la tierra, porque los demás pueblos vecinos apreciaban la tierra de Chilacachapa (Leal, 2011: 12, entrevista a Efraín Herrada).

[...] en los años 70 estaba Genaro Vázquez. Genaro Vázquez, fue rescatado de la prisión de Iguala si mal no recuerdo el 18 de abril del 68, un comando armado lo rescata [...] estuvo en Chilacachapa y me acuerdo de niño que nos decían: ¡mira ese es Genaro!, ahí estaba con Chicho, Lucio [...] Incluso en ese comando armado que rescata a Genaro participó un estudiante de Chilacachapa [...] Después de Chilacachapa, Genaro se va a la cabecera municipal de Cuetzala, concretamente a buscar el apoyo de Macrina Rabadán, que fue la primera diputada lideresa del PPS [oriunda de Cuetzala] (Leal, 2011: 12, entrevista a Tiburcio Simbrón).

Resalta de lo anterior, la vigencia de los recuerdos por parte de los integrantes de la Asociación, quienes conectan, por decirlo de alguna manera, sus acciones presentes con personajes, acontecimientos y situaciones del pasado, pero que adquieren significado en el marco de las situaciones específicas que enfrentan en este caso en su nicho ocupacional y desde donde también encuentran sentido y además justifican sus formas organizativas. Al respecto, señala James Clifford (2013: 25) para el caso de los indígenas Kame`eleihiwa: “'el futuro es siempre lo no escrito'; ya que dichos indígenas no invocan la repetición de ciclos recurrentes, es decir, para este grupo no se trata simplemente de repetir las formas del pasado, sino que el presente implica una selección práctica y crítica de recordar las raíces”. Los cambios que observa operan en las prácticas concretas, las cuales dan cuenta de una tradición vivida, donde algunos elementos pueden ser activamente recordados, otros olvidados y algunos más, apropiados por influencias extranjeras o incluso ser trasladados desde otras narraciones análogas.

Como veremos a continuación, los chilas recrean historias particulares y grupales sobre hechos y acontecimientos que han vivido tanto en el pueblo de origen como en la ciudad. Dichas 
historias se han convertido en patrimonio de su memoria colectiva, aunque sus formas discursivas se han modificado dependiendo de la situación presente que se enfrente y, particularmente, si las mismas se han impulsado para establecer alianzas, acuerdos, justificar acciones, resaltar diferencias con relación a otros grupos, solicitar beneficios, entre otros. No parten, por lo tanto, de una narración de acontecimientos históricos lineales, sino que recrean y resaltan hechos, siempre vinculándolos con un contexto más amplio, como puede ser el ámbito regional para el caso del estado de Guerrero o bien las formas estructurales que han identificado desde su asentamiento en la ZMVM. Partiendo de lo anterior, y volviendo a la historia de la Asociación, varios de sus integrantes tejen claramente los momentos y causas que detonaron diversos procesos organizativos desde que arribaron a la ciudad de México durante el último tercio del siglo pasado. También reconocen claramente la diferencia en la preparación educativa de las generaciones recientes, quienes han impulsado otras formas de liderazgo, dependiendo sus procesos diferenciados de inserción en la urbe.

\section{La emergencia de sentidos étnicos en el contexto urbano}

El tipo de narraciones expresadas por los chilas sobre su asentamiento en la ciudad de México dan cuenta de un imaginario desde donde explican la reproducción de ciertas prácticas de organización tradicional, nutridas por historias donde narran la existencia de grandes líderes que encabezaron luchas en el pueblo, así como de personajes importantes oriundos del estado de Guerrero. Además, cuando se trata de tomar decisiones en beneficio común, tanto en el Comité vecinal como en la Asociación de revistas, los líderes chilas discursivamente impulsan la figura de la asamblea comunitaria bajo los preceptos de su funcionamiento en el pueblo de origen Chilacachapa. No obstante, como se describirá en los siguientes párrafos, los mecanismos para organizarlas y tomar acuerdos en la ciudad son diferentes, sobre todo porque sus agremiados si bien son principalmente residentes chilas también proceden de otros distintos orígenes y adscripciones étnicas.

Pero lo cierto es que las condiciones de sobrevivencia en la urbe los ha llevado a reinventar prácticas o, en su caso, crear nuevas y establecer alianzas con “otros” bajo lógicas de organización que no necesariamente responden a las formas imperantes en la comunidad de origen. Por ejemplo, la organización política-administrativa en el pueblo de Chilacachapa descansa en dos figuras centrales: comisario municipal y comisario de bienes comunales. Cargos que, si bien se eligen por votación, quienes participan en la elección deben cubrir ciertos requisitos; es decir, aquellos que migraron han perdido derechos al dejar de considerarlos como ciudadanos. Además, el sistema de tenencia de la tierra no es de propiedad ejidal, sino comunal, y, por lo tanto, solo perteneciente a quienes se reconocen como comuneros; es importante aclarar que únicamente quienes aparecen registrados en el padrón como comuneros pueden ejercer voto para la elección del comisario de bienes comunales. Ante tales requisitos, por lo menos en la comunidad de Chilacachapa, no todos pueden votar. Por lo tanto, en el discurso de varios chilas, la asamblea - como espacio colectivo en la toma de decisiones - tiene alcances diferenciados. Primero, cuando la refieren una vez asentados en la ciudad y, segundo, si se trata de la gestión en beneficio

EntreDiversidades. Revista de Ciencias Sociales y Humanidades, Vol. 8, Núm. 2 (17), julio-diciembre 2021. Páginas: 6-29 ISSN-e: 2007-7610. https://doi.org/10.31644/ED.V8.N2.2021.A01 
de obras y programas sociales, como el caso del Comité vecinal de la colonia Vista Hermosa, en Cuautepec, o bien en el caso de la Asociación de revistas, donde la toma de decisiones se realiza a través de la asamblea de los agremiados.

En torno a la presencia de nuevos líderes que encabezaron las luchas por la defensa de la vivienda en zonas céntricas de la ciudad hacia mediados de la década de los ochenta, de manera particular destaca el trabajo de dos chilas: Fortino y Javier. Con relación a su labor organizativa, el señor Efraín refiere: "los pioneritos les llamábamos, al Fortino y sus dos cuates”, debido a que empezaron a sobresalir como líderes siendo muy jóvenes, al proponer nuevas formas de gestión y lucha social, y además accedieron a otros niveles educativos en comparación con las generaciones anteriores, quienes, como ya comentamos, también estaban luchando en la organización de revistas pero enfrentando problemas para su operación. Ante estos diversos escenarios de desafiar las luchas sociales en la ciudad, el mismo Efraín concluye: "no teníamos la capacidad política, ni la visión para detectar problemas, sino que los detectamos muy tarde".

Sobre cómo se da una concatenación de procesos organizativos que precisamente ilustran lo que llamo trayectorias cruzadas de ciudadanización de forma temprana a su arribo a la ciudad por parte de los chilas, el caso de Fortino es ilustrador, ya que su formación parte de escolarizarse en la Preparatoria Popular Tacuba y de fundar la Unión de Inquilinos de la Colonia Pensil, donde radicaban decenas de familias chilas y que para mediados de los años ochenta se pretendió su desalojo.

[En la colonia Pensil] Ahí era otra comunidad de Chilacachapa, en su mayoría un 70\% era de Chilacachapa, y si nos desviamos un poquito en cómo llegaron, cómo se va formando; porque los paisanos que llegan de Chilacachapa aquí, buscan primero un lugar para rentar, llegan y con un familiar piden permiso por unos días por temporadas porque explican: yo soy campesino, trabajo el campo [...] entonces nada más es hacer un dinerito y regresar allá, pero ya ve que su condición de vida va cambiando y dice bueno, por qué no me consigues un cuarto y voy por mi familia y ya teniendo el cuarto pues me traigo los parientes, amigos... Entonces, llega el momento de que los vecinos de la colonia Pensil, los que administran prácticamente eran los de Chilacachapa, eran los responsables de pasar a cobrar la renta para que la dueña llegue solo a recogerla, porque los paisanos de Chilacachapa son trabajadores, no importa qué área, en su mayoría vendían periódico, ya empezaban a vender revistas, dulces en las avenidas, en las esquinas y limpiadores de autos los más niños, entonces era un actividad muy, muy productiva (Leal, 2011: 14, entrevista a Alberto Ortega).

Destaca de lo anterior la formación de liderazgos entre los chilas y el reconocimiento hacia el trabajo de cada uno. Si bien personalmente me he acercado más a quienes trabajan en el ámbito de la gestión social, resulta importante conocer otros escenarios sociales erigidos también con tenacidad y lucha cotidiana, y que ellos mismos refieren como "otra lucha", "otro campo de acción", que incluso suma o potencia la lucha colectiva. Lo trascendente de los testimonios es la identificación de cualidades y acciones emprendidas por cada quién. Alude a una especie de reconocimiento colectivo, pero diferenciando las cualidades individuales acumuladas por un capital propio y de

EntreDiversidades. Revista de Ciencias Sociales y Humanidades, Vol. 8, Núm. 2 (17), julio-diciembre 2021. Páginas: 6-29 ISSN-e: 2007-7610. https://doi.org/10.31644/ED.V8.N2.2021.A01 
acción social. Esta última dimensión es lo que dotaría de contenido la propuesta de "sentidos étnicos", esto es, una relación entre reconocimiento colectivo y atribuciones individuales y luchas personales en una dirección de acumulación de capital social y político — donde además se cruzan actitudes de empatía y afectos hacia ciertos hombres y mujeres, incluso familias, dependiendo de sus acciones en diversos campos de lucha social- Esto, también conlleva al análisis de la acción individual de los sujetos étnicos. Los capitales no solo se ponen en juego al interior del mismo colectivo chila, sino, más importante aún, se utilizan con otros sujetos no chilas. Ello, con el fin de obtener beneficios de diversa índole. Incluso podemos decir que se preocupan por mantener esas alianzas y alimentarlas de forma permanente. ${ }^{8}$

Así también, el caso de los chilas nos permite analizar lo que podríamos llamar procesos de formación ciudadana, tejidos desde su origen étnico pero renovados desde sus formas de inserción ocupacional en la ciudad, así como desde los mecanismos de agrupación generacional dotados de fuertes cargas de socialización para aprender a desenvolverse en la urbe. El extenso testimonio de Vicencio que se presenta a continuación nos muestra claramente su aprendizaje e involucramiento en tareas de organización y lucha gremial, además de ejemplificar cómo se va acumulando capital social y político en las trayectorias de ciudadanización de varios chilas.

Mi nombre es Vicencio Peralta Rodríguez, de Chilacachapa también. Yo hace 17 años (1994) también me incorporé a esta agrupación con la idea de vender las publicaciones atrasadas. Vine, solicité mi permiso que aquí los representantes se encargaron de tramitarlo ante las autoridades y pues me dijeron: "ya ponte". Conseguí mi casetita y pues ahí inicié hace 17 años y ahí poco a poco unos compañeros de la mesa directiva, pues me iban invitando a que participara en algunas comisiones como precio-propaganda. Yo recuerdo bien que también el compañero Carlos, pues me invitaba, me decía: "ven compañero, vamos a pegar cartulinas; donde esas cartulinas se pegan en las bodegas, para que vean los compańeros que estamos convocando a una asamblea general". De esa manera me fui involucrando, después me dieron una cámara para que yo la manejara y yo era también el fotógrafo de la Unión. En cada salida que hacíamos yo tomaba fotografías y esto ha quedado ahorita como archivo y así poco a poco pasaron los años. Me invitaron también a las asambleas, porque cuando yo llegué, a mí me daba miedo hablar, me temblaba el cuerpo, pero me decían los compañeros ¡vamos, vamos! A una reunión en una delegación y a mí me daba mucho miedo, y después pasaron los años y me invita un compañero a que lo acompañe en su administración en el cargo de secretario y bueno, me encantó. Trabajé con él en el ańo 2007-2008 como secretario general, a finales del 2008 me eligen para ser presidente de esta agrupación, bueno lo decidió la gente y los compañeros vendedores y adelante, otros dos años me quedé en el cargo, dos años como secretario, dos como presidente y a la vez aquí aprendí cosas nuevas tanto cómo gestionar un permiso, un trámite ante las autoridades de la Secretaria del Trabajo, ante las delegaciones y a mí me encantó, porque me relacioné con todas las autoridades de las delegaciones, sí, siendo algunos del PAN, por ejemplo en la Miguel Hidalgo,

\footnotetext{
${ }^{8}$ Una propuesta interesante que abona en el análisis de la construcción de relaciones afectivas en las familias indígenas y el papel que juegan en la reproducción de sus identidades étnicas lo desarrolla Chávez (2013), para el caso de indígenas urbanos en la ciudad de San Luis Potosí.
}

EntreDiversidades. Revista de Ciencias Sociales y Humanidades, Vol. 8, Núm. 2 (17), julio-diciembre 2021. Páginas: 6-29 ISSN-e: 2007-7610. https://doi.org/10.31644/ED.V8.N2.2021.A01 
ahí siempre ha gobernado el PAN pero nos daban buen trato los políticos, la jefa delegacional, y bueno, igual ahorita con el PRD, vamos a la delegación GAM [...] A mí me tocó también en ese periodo que estuve aquí, pues me tocó ver lo más difícil: la economía, la ausencia de la gente, de los asambleístas y bueno los sigo motivando, invitando y poco a poco iban llegando nuevamente y en la actualidad aquí estamos, la gente viene a las asambleas. Las asambleas se realizan una vez al mes. Ellos (los agremiados) vienen a escuchar el informe de la mesa directiva que está representando actualmente. Les informan de cuestión finanzas, problemas de sueldos, pendientes, todo eso aquí. Nos damos cita todos los viernes a fines de mes a las seis de la tarde [...] [ya que] este pequeño auditorio no es privacidad de nadie [oficina ubicada en la calle de Tacuba], sino que es de todos los revisteros, porque todos somos vendedores y aquí nos damos cita o si algún compañero anda por acá en el Centro Histórico, pues tiene todo el derecho de venir a descansar un ratito, aquí en su oficina y por eso digo, que este auditorio es la casa de todos. Pero también en esas fechas me tocó expulsar al compañero Fortino. Fortino es un líder que también él perteneció aquí, pero también el reglamento lo marca; o sea los compañeros que no cumplen con sus cuotas de asistencia, tenemos que excluirlos de nuestra organización. Sí, para mí fue muy difícil excluir también al compañero, pero también con la voz y voto de todos los asambleístas, ellos dicen qué es lo que se tiene que hacer en esta agrupación y bueno, eso es parte del trabajo (Leal, 2011: 15-16, entrevista a Vicencio Peralta Rodríguez).

El testimonio de Vicencio también clarifica cómo los chilas desde hace varias décadas se han venido relacionando con diversas instancias del gobierno local, en un inicio asumiendo un papel como demandantes de información, sin contar con asesoría y teniendo escasos recursos educativos, hasta convertirse en los últimos años en activos gestores, manteniendo interlocución permanente no solo con instancias administrativas de diversas dependencias locales, sino sumando apoyos con otras agrupaciones sociales, ya sea porque son paisanos guerrerenses, porque se agrupan en asociaciones de inquilinos, simpatizan con ciertas corrientes preferentemente perredistas (y desde el 2017, con el partido Morena), o bien porque se identifican con ciertos gremios de trabajadores. Dependiendo la coyuntura, apoyan o encabezan ciertas luchas y una vez resueltas determinadas demandas se disgregan y/o atienden otras. Este dinamismo en las formas de participación es lo que, considero, impacta en que grupos y actores no chilas los refieran siempre como líderes de ciertos procesos organizativos, o bien, se adscriban e incluso se subsuman a las formas de organización que ellos proponen.

Asimismo, la importancia del testimonio de Vicencio radica en que expresa claramente la conformación de los chilas en el tema de la gestión social y, particularmente, cómo se da su proceso de formación política. Destaca la forma en que se impulsa y se acompańa a los nuevos participantes, por lo que podemos hablar de una socialización entre los chilas para la gestión. Es decir, cómo se concibe la formación, el espacio/local de la Unión, cómo se desplazan de los intereses individuales a los colectivos y cómo se justifican sus acciones al resaltar que es la fuerza de la idea de lo colectivo lo que se mueve: "la organización me dice qué debo hacer" - comenta Vicencio- y si lo hace, entonces, en otros espacios de lucha social se asumen como sus representantes. Representantes, por lo tanto de lo colectivo. Pero también y muy importante,

EntreDiversidades. Revista de Ciencias Sociales y Humanidades, Vol. 8, Núm. 2 (17), julio-diciembre 2021. Páginas: 6-29 ISSN-e: 2007-7610. https://doi.org/10.31644/ED.V8.N2.2021.A01 
nos ilustra cómo se reajustan los liderazgos dependiendo el espacio de agrupación y los deberes que se asumen ante los agremiados, o en el caso del comité vecinal, ante los vecinos participantes. Lo anterior se destaca ya que como lo comentamos, los chilas encabezan dichas agrupaciones, pero en ambos casos no las integran únicamente chilas.

Con relación a la última parte del testimonio de Vicencio, donde refiere la expulsión de Fortino de la Asociación de revistas, el mencionarlo por parte del entrevistado se debe a varias consideraciones; primero, que, como ya se comentó, Fortino representa una figura central en las luchas que han encabezado los chilas en las últimas dos décadas en la ciudad de México. De hecho, en el acta constitutiva de la Asociación de revistas, él aparece como el primer integrante de la asociación, lo cual habla de su presencia activa durante la primera etapa de conformación hacia fines de los años ochenta, que se reconoce por varios de los agremiados y comentado en anteriores párrafos. El segundo elemento que interviene es que entre ambos media una relación de parentesco, al ser cuñados, y tercera, que los dos viven en la colonia Vista Hermosa, donde Fortino es uno de los líderes más importante en el comité vecinal de la colonia. En este sentido, son varios los planos que se cruzan para delimitar las jerarquías entre los integrantes de ciertas asociaciones, dependiendo los derechos y obligaciones delimitados por los mismos participantes. Asimismo, da cuenta de la diversidad de planos en la toma de decisiones, dependiendo si para determinados momentos uno u otro mantiene liderazgo y de cómo se justifican ciertas acciones. De ahí la frase "para mí fue muy difícil excluir también al compañero, pero también con la voz y voto de todos los asambleístas, ellos dicen qué es lo que se tiene que hacer en esta agrupación y bueno, ese es parte del trabajo". ' Además, agregaría que Vicencio por el mismo periodo que fungía como presidente de la Asociación de revistas también fue nombrado presidente del comité vecinal de la colonia Vista Hermosa. De hecho, relevó a Fortino en la presidencia del mismo, lo cual, sin duda, sumó inquietud sobre cómo manejar la expulsión de Fortino del gremio de revisteros, pero al mismo tiempo mantuvo una comunicación permanente con él, en los asuntos vecinales. Por otro lado, su caso nos ayuda a entender cómo se da el tránsito de los chilas entre un colectivo de lucha entre un ámbito y otro, que puede o no coincidir temporalmente o bien escalonarse y con ello utilizar la formación previa para un mejor desempeño en la gestión social, ante la posibilidad de asumir nuevas tareas.

Concluyo este apartado con una caracterización que el mismo Vivencio realiza de sus paisanos chilas y en particular de los agremiados en torno a la Asociación de revisteros:

Vicencio: Yo vivo en Vista Hermosa, allá vivo, somos de allá, por eso a veces nos ven allá, nos ven aquí y en otros lados, pero así somos los chilas... Muchos en otros lados se sorprenden mucho de ¿por qué los chilas tienen casa, carro? Y así somos, somos bien trabajadores; nos levantamos temprano y llegamos tarde a la casa y bueno, como dicen los compañeros, en el tiempo que nos fue bien todos hicimos algo, aquí nadie se quedó sin hacer nada, aquí todos hicieron algo en

\footnotetext{
${ }^{9}$ Esta información, se conecta con otro nivel de análisis que no abordaré en este trabajo, pero que se refiere a las categorías que predominan en el padrinazgo y compadrazgo entre los chilas, pues dependiendo el tipo de festejo y si son padrinos, invitados o familiares, en cada fiesta asumen diferentes roles, de tal suerte que a veces son las figuras centrales de la celebración y en otros como ellos señalan "les toca servir y atender a los invitados y padrinos".
}

EntreDiversidades. Revista de Ciencias Sociales y Humanidades, Vol. 8, Núm. 2 (17), julio-diciembre 2021. Páginas: 6-29 ISSN-e: 2007-7610. https://doi.org/10.31644/ED.V8.N2.2021.A01 
esa época, pero bueno ahorita, sí, las ventas cayeron, el internet nos dio en la torre, pero aquí estamos; nos estamos agrupando, nos estamos viendo y quien está aquí en esta oficina no es porque le estén pagando, sino que está dando algún servicio a nuestra agrupación [...] (Leal, 2011: 17, entrevista a Vicencio Peralta Rodríguez).

\section{Consideraciones finales: los chilas y sus procesos de etnicidad urbana}

A partir de los diversos testimonios que se narraron en los apartados anteriores, retomo de nueva cuenta el contenido del término identificación propuesto por Brubaker y Cooper (2005), pero ahora incluyendo otra dimensión de análisis relacionada con su significado psicodinámico, el cual retoman de Freud. Si bien no desarrollan cómo se da esta articulación, ni cuáles son sus fundamentos, básicamente se refieren a las implicaciones de los sujetos al identificarse afectivamente con otra persona, categoría o colectividad. ${ }^{10}$ Esto último lo retomo porque las descripciones presentadas en los párrafos anteriores, incluyen referencias de este nivel, no solo en una dimensión desde sí mismo, como chilas, sino que también lo expresan de alguna forma los "otros" cuando establecen identificaciones hacia los chilas. En este punto podemos decir que también están cargadas en algún sentido de afectividad, la cual en un primer acercamiento al caso referí como valores, siendo el respeto y la solidaridad los más destacados, referentes que muy pronto me percaté no eran suficientes para entender el tipo de interacciones sociales que se han generado entre los chilas y con otros sujetos y actores, las cuales he observado remiten en algún sentido a expresiones afectivas. Me refiero, por ejemplo, a la frase expresada por Vicencio como "me encantó", para expresar el momento en que encontró sentido a su trabajo como integrante de la mesa directiva y valoró de forma positiva el apoyo de sus compañeros y paisanos del gremio para ocupar diversos cargos.

Incluso si se retoma otra de las categorías que proponen Brubaker y Cooper, podemos encontrar un puente entre este nivel afectivo y las diversas adscripciones por las que puede optar un sujeto étnico. Me refiero al término "autocomprensión”, que para el caso chila resulta fundamental para entender las historias individuales de militancia y logros reconocidos abiertamente por otros chilas. Así, es en este nivel donde podemos ubicar una diferencia sustancial para realizar un análisis de los sujetos chilas y sus acciones individuales, o bien cuando actúan como colectivo. Sobre el término autocomprensión, dichos autores refieren lo siguiente:

\footnotetext{
${ }^{10}$ Para Stuart Hall, la identificación desde el sentido común, "se construye sobre la base del reconocimiento de algún origen común o unas características compartidas con otra persona o grupo o con un ideal, y con el vallado natural de la solidaridad y la lealtad establecidas sobre este fundamento. En contraste, el enfoque discursivo ve a la identificación como una construcción, un proceso nunca terminado: siempre 'en proceso' [...] la identificación es en definitiva condicional y se afinca en la contingencia. Una vez consolidada no cancela la diferencia. La fusión total que sugiere es, en realidad, una fantasía de incorporación [...] La identificación es, entonces, un proceso de articulación, una sutura, una sobredeterminación y no una subsunción" (2003: 15). Apunto esta consideración para contextualizar el interés por incorporar una dimensión subjetiva en el análisis sobre los sujetos chilas en términos de comprender sus trayectorias de vida y la relación que podemos observar con diversos niveles de identificación individual y colectiva.
}

EntreDiversidades. Revista de Ciencias Sociales y Humanidades, Vol. 8, Núm. 2 (17), julio-diciembre 2021. Páginas: 6-29 ISSN-e: 2007-7610. https://doi.org/10.31644/ED.V8.N2.2021.A01 
El término "autocomprensión", hay que destacarlo, no implica una concepción del yo como una entidad homogénea, limitada y unitaria, propia del mundo moderno u occidental. La percepción que se tiene de sí puede asumir muchas formas diversas. Los procesos sociales a través de los cuales las personas se entienden y se ubican, pueden, en algunos casos, necesitar el diván del psicoanalista y, en otros, la participación en cultos de posesión espiritual. Según las configuraciones, las personas pueden concebirse, experimentarse a sí mismas en términos de un escalafón de categorías entrecruzadas o en términos de una red de conexiones de diferente proximidad e intensidad. De aquí la importancia de ver a la autocomprensión y la localización social en relación la una con la otra y de enfatizar que tanto el "yo" limitado como el grupo cerrado son peculiaridades culturales más que formas universales (2005: 196).

En ese punto donde se plantea el "yo" como una entidad no homogénea, no limitada y no unitaria como señalan los autores, concibo un punto explicativo para analizar el proceder de los chilas en los espacios donde se encuentran con la alteridad, que si bien los otros pueden llegar a ubicarlos como una "comunidad chila", lo cierto es que los intereses personales pueden o no coincidir con los grupales. Por grupales me refiero no a todos los sujetos que se autoidentifican como chilas radicados en la ZMVM, sino a aquellos que se agrupan en torno a un aspecto en particular: un nicho laboral, la permanencia de redes de parientes y compadres, la reproducción de festejos que condensan la vida religiosa y cívica del pueblo, entre otros. Es aquí donde podemos ubicar la individualidad del sujeto étnico que se adscribe a ámbitos diferenciados y cuya participación activa o no activa depende de sus afectividades, de sus intereses, de su disposición de tiempo, de relaciones jerárquicas entre paisanos y parientes, o bien entre rivales políticos, entre otros.

$\mathrm{Al}$ respecto y retomando de nueva cuenta el testimonio de Vicencio, este permite destacar la importancia de analizar al individuo como agente empírico, quien al desempeñar diversos papeles se inserta en una red de parentesco, fundamental para seguir reproduciendo procesos de sociabilidad urbana, pero que como en el caso de los chilas, no se agota en este universo, sino que se entrelaza con otras redes y, por lo tanto, sus esferas de acción se vuelven más complejas y densas.

Por otro lado, un tema que preocupa a los dirigentes de la Asociación de revistas, al que alude Vicencio en los últimos renglones de su testimonio, se refiere al impacto que las nuevas tecnologías están teniendo en su nicho laboral. Lo anterior cobra sentido a partir de conocer el funcionamiento inicial de este negocio y cómo principalmente durante la década de los años noventa los chilas sacaron ventaja económica, lo cual les coadyuvó a comprar terrenos, departamentos de interés social, o bien edificar con mejores materiales sus viviendas.

Se puede decir que el devenir de los chilas, por lo menos de aquellos ocupados en la venta de revistas, se encuentra en un proceso de redefinición de estrategias de sobrevivencia, las cuales, sin duda, encontrarán nuevas vías de reproducción a partir de recuperar su capital organizativo y de conocer los vaivenes de la economía de la ciudad y en general de los procesos de organización gestados en diversos puntos de la zona metropolitana donde se asientan.

Para ir concluyendo este escrito, señalaría que el caso de la Asociación de revistas donde participan un número importante de hombres y mujeres chilas me llevó a problematizar el tema

EntreDiversidades. Revista de Ciencias Sociales y Humanidades, Vol. 8, Núm. 2 (17), julio-diciembre 2021. Páginas: 6-29 ISSN-e: 2007-7610. https://doi.org/10.31644/ED.V8.N2.2021.A01 
de sus adscripciones identitarias, ya que por momentos, como lo señalé en otro apartado, estos destacan su pertenencia étnica, pero en otras ocasiones su adscripción de clase o sus simpatías por ciertos gremios ocupacionales. Dependiendo la calidad y cualidad de sus interacciones con sus propios paisanos y con otros actores y sujetos el contenido de sus discursos y sus acciones concretas de organización se transforman significativamente.

Por lo anterior, no bastaba con señalar que los chilas asociados en torno a la agrupación de revistas generan diversas identidades sociales; de alguna manera resultaba poco novedoso su abordaje analítico. De ahí que recuperar y optar por la categoría de identificación propuesta por Brubaker y Cooper me permitiera enriquecer el análisis, en el sentido de que para hablar de la misma se requiere especificar a los agentes que llevan a cabo la tarea de identificar. No obstante, desde esta propuesta la identificación no requiere un "identificador" específico; puede insinuarse y ejercer su influencia sin ser realizada por personas o instituciones determinadas y específicas. Se puede llevar a cabo de forma más o menos anónima por mediación de discursos y de narrativas públicas (Brubaker y Cooper, 2005: 195). Esto último también lo señala Stuart Hall cuando refiere que la cuestión de la identificación alude a rearticular la relación entre sujetos y prácticas discursivas (2003: 15). Las anteriores referencias conceptuales, por lo tanto, las tuve presentes para analizar los procesos organizativos, así como los discursos construidos por los chilas en torno a sus identificaciones individuales y colectivas, que resaltan sobre todo por su capacidad de agencia en la negociación política.

Un segundo elemento de análisis se refiere al uso que realizan los chilas y los agremiados de los espacios públicos en la ciudad y su apertura al establecimiento de alianzas con otros grupos y sectores institucionales. Lo anterior, de nueva cuenta resalta el tema de la gestión social como uno de los mecanismos más relevantes para el logro de beneficios individuales y colectivos, que requiere niveles de especialización importantes en el terreno de la administración pública e institucional.

El tercer componente se refiere la historia del surgimiento y consolidación de la Asociación, que destaca porque cada uno de los primeros integrantes chilas que conformaron este grupo de revisteros acumulan historias particulares de lucha social en diversos campos de participación social, por lo menos desde la década de los 80 del siglo XX hasta la actualidad (inquilinaria, agraria, de ayuda al pueblo, festividades, política). Esto alimenta lo que llamé en otro apartado "historias cruzadas de lucha social y política” por parte de los chilas desde su arribo y permanencia en la Ciudad de México. Como se observó, algunos hombres han participado de forma simultánea en diversos tipos de colectivos, cuyos fines de lucha por momentos se complementan o bien sirven como experiencia previa para poder escalar y participar en puestos, comisiones y asambleas, dependiendo de la situación. Su implicación ha dependido también del tipo de relación que se establece con las dependencias de gobierno y autoridades locales, en este caso directamente vinculadas con la operación de puestos fijos donde se venden revistas y libros en calles y avenidas primarias en toda la Ciudad de México, pero de manera primordial en las zonas centro y norte de la capital. Por todo lo anterior, el caso de la Asociación de revistas destaca de manera clara por la formación de cuadros en la gestión social entre los chilas a partir de la reconfiguración de los significados sobre su origen nahua en el estado de Guerrero, pero anclados en un universo urbano

EntreDiversidades. Revista de Ciencias Sociales y Humanidades, Vol. 8, Núm. 2 (17), julio-diciembre 2021. Páginas: 6-29 ISSN-e: 2007-7610. https://doi.org/10.31644/ED.V8.N2.2021.A01 
que ha afianzado su politización en el gremio y/o desde el gremio ocupacional, dependiendo de sus vínculos en otros ámbitos de la vida social. Indudablemente, ellos mismos manifiestan sus motivaciones y sus identificaciones en función de la circunstancia, destacando su diferencia étnica, su ser chila, o bien reconociendo su pertenencia como individuos, trabajadores y/o consumidores.

Por último, a través de sus testimonios resaltan dimensiones afectivas sobre el proceso mismo de formación política, por ejemplo, al reconocer a los compañeros, paisanos, parientes, que han apoyado y enseńado distintas estrategias de lucha social y desde las cuales han podido acceder a beneficios colectivos, aunque no dejen de presentarse competencias y discrepancias entre ellos. La categoría de sentidos étnicos justamente refiere a estas dimensiones afectivas y de reconocimiento entre los chilas. Sin duda, esta dimensión de análisis ha sido poco explorada en los estudios sobre etnicidad urbana. Es en torno a estas interconexiones analíticas que se puede impulsar una agenda de investigación.

\section{Bibliografía citada}

Bloul, Rachel A. D. (1999). "Beyond Ethnic Identity: Resisiting Exclusionary Identificaction”. Social Identities, 5 (1), pp.7-30. También disponible en: https://doi. org/10.1080/13504639951590

Brubaker, Rogers y Cooper, Frederick (2005). "Más allá de la identidad”, en Wacquant, Loïc (coord.). Repensar los Estados Unidos. Para una sociología del hiperpoder. Barcelona, España: Anthropos Editorial, pp. 178-208.

Clifford, James (2013). Returns. Becoming Indigenous in the Twenty-First Century. Harvard, United States of America: University Press.

Chávez González, Mónica (2013). "La familia, las relaciones afectivas y la identidad étnica entre indígenas migrantes urbanos en San Luis Potosî". Relaciones. Estudios de historia y sociedad [en línea], 34 (134), pp. 131-155. Disponible en: http:/www.revistarelaciones.com/ index.php/relaciones/article/view/462/699 (Consultado el 31 de octubre de 2020).

Chávez González, Mónica (2014). Identidad étnica, migración y socialización urbana. Profesionistas indígenas de la Huasteca en la capital potosina. México, D.F., México: Centro de Investigaciones y Estudios Superiores en Antropología Social.

Díaz Vázquez, Rosalba (2015). "Migración, cohesión social e identidad étnica entre los nahuas de Acatlán Guerrero, en la ciudad de México". Rutas de Campo [en línea], Año 2, Núm. 6, enero-febrero, pp. 52-55. Disponible en: https://revistas.inah.gob.mx/index.php/ rutasdecampo/issue/view/696/697 (Consultado el 12 de abril de 2021).

Durin, Séverine (2010). Etnicidades urbanas en las Américas. Procesos de inserción, discriminación y politicas multiculturalistas. México, D.F., México: Publicaciones de la Casa Chata, Centro de Investigaciones y Estudios Superiores en Antropología Social.

EntreDiversidades. Revista de Ciencias Sociales y Humanidades, Vol. 8, Núm. 2 (17), julio-diciembre 2021. Páginas: 6-29 ISSN-e: 2007-7610. https://doi.org/10.31644/ED.V8.N2.2021.A01 
Gissi Barbieri, Nicolás (2009). Sistemas de intercambio económico, redes sociales e integración urbana de la población mixteca y chocholteca en la colonia San Miguel Teotongo, Ciudad de México. Tesis para obtener el grado de Doctor en Antropología, Instituto de Investigaciones Antropológicas, Universidad Nacional Autónoma de México. También disponible en: http://132.248.9.195/ptd2009/junio/0645328/Index.html

Gissi Barbieri, Nicolás (2012). “¿Movilidad social ascendente en los indígenas urbanos contemporáneos? Don, mercado e inserción social entre los mixtecos de Ciudad de México”. Atenea, Núm. 506, pp. 71-95. También disponible en: http://dx.doi. org/10.4067/S0718-04622012000200006

Gutiérrez Sánchez, Javier (2013). Construcciones de espacios, poderes y fronteras. Territorializaciones Batsi'i Viniketik en San Cristóbal de las Casas y tseltales en Ocosingo. Chiapas, México: Universidad Nacional Autónoma de México. También disponible en: https://www. posgrado.unam.mx/publicaciones/ant col-posg/44 Construcciones.pdf

Hall, Stuart (2003). "Introducción: ¿quién necesita 'identidad'?” en Hall, Stuart y du Gay, Paul (comps.). Cuestiones de identidad cultural. Buenos Aires, Argentina: Amorrortu editores, pp. 13-39.

Herrera Amaya, María Elena (2018). "Comunidades indígenas urbanas: disputas y negociación por el reconocimiento”. Andamios, 15 (36), enero-abril, pp. 113-134. doi: http://dx.doi. org/10.29092/uacm.v15i36.604 (Consultado el 12 de marzo de 2021).

Hiernaux, Daniel (2000). Metrópoli y etnicidad: Los indígenas en el Valle de Chalco. México, D.F., México: El Colegio Mexiquense.

Leal Sorcia, Olivia (2014). Reconocimiento étnico y periferias multiculturales: los chilas (nahuas) en Cuautepec, Ciudad de México. Tesis para obtener el grado de Doctora en Ciencias Sociales. El Colegio de Michoacán.

Leal Sorcia, Olivia (2015). "Enclave migratorio de nahuas oriundos de Chilacachapa, Guerrero, en la colonia Vista Hermosa, Distrito Federal”. Rutas de Campo [en línea], Año 2, Núm. 6, enero-febrero, pp. 63-71. Disponible en: https://revistas.inah.gob.mx/index. php/rutasdecampo/issue/view/696/697 (Consultado el 12 de abril de 2021).

Leal Sorcia, Olivia (2019). "Indígenas nahuas y sus procesos de etnicidad urbana en la ciudad de México”. Revista Antropologías del sur [en línea], 6 (11), pp. 199-221. Disponible en: http://revistas.academia.cl/index.php/rantros/article/view/1055/1307 (Consultado el 24 de febrero de 2021).

Martínez Casas, Regina (2007). Vivir invisibles. La resignificación cultural entre los otomies urbanos de Guadalajara. México, D.F., México: Publicaciones de la Casa Chata, Centro de Investigaciones y Estudios Superiores en Antropología Social.

Molina, Virginia (2006). Condiciones sociales y dinámica de la población indígena en centros urbanos. Estudio Nacional. México, D.F., México: Comisión Nacional para el Desarrollo de los Pueblos Indígenas (documento interno).

EntreDiversidades. Revista de Ciencias Sociales y Humanidades, Vol. 8, Núm. 2 (17), julio-diciembre 2021. Páginas: 6-29 ISSN-e: 2007-7610. https://doi.org/10.31644/ED.V8.N2.2021.A01 
Morales Muñoz, Marco Vinicio (2018). "Etnicidad y nuevos espacios de participación política y ritual de las mujeres Rarámuri en los asentamientos de la ciudad de Chihuahua”, Andamios, 15 (36), enero-abril, pp. 67-91. doi: http://dx.doi.org/10.29092/uacm. v15i36.602 (Consultado el 16 de octubre de 2020).

Morán Pérez, Ana y Ruelas Takayasu, Atsumi (2019). "Diversidad y heterogeneidad de los indígenas en la delegación Tlalpan. Una riqueza cultural”, en Pérez Téllez, Iván (coord.). Indígenas Urbanos. Proyecto de investigación etnográfica de la Ciudad de México. Ciudad de México, México: Secretaría de Cultura, Gobierno de la Ciudad de México, pp. 66-91. Disponible en: $\quad$ https://redmifa.blog/2019/06/04/indigenas-urbanos-proyecto-de-investigacionetnografica-de-la-ciudad-de-mexico/ (Consultado el 4 de noviembre de 2020).

Oehmichen, Cristina (2010). "Espacio urbano y segregación étnica en la ciudad de México". VillaLibre. Cuadernos de estudios sociales y urbanos, Núm. 6, pp. 61-75. Disponible en: http://www.iia.unam.mx/directorio/archivos/OEBC581012/2010-villalibre 6.pdf (Consultado el 3 de diciembre de 2020).

Peña, Guillermo de la (2010). “¿Una nueva categoría analítica? Los indígenas urbanos en la antropología mexicana”, en Esteva-Fabregat, Claudio (coord.). La antropología y la consciencia mexicana. Guadalajara, México: El Colegio de Jalisco, pp. 213-240.

Pérez Ruiz, Maya Lorena (2008). "Diversidad, identidad y globalización. Los jóvenes indígenas en las ciudades de México”, en Pérez Ruiz, Maya Lorena (coord.). Jóvenes indígenas y globalización en América Latina. México, D.F., México: Instituto Nacional de Antropología e Historia, pp. 45-67. También disponible en: http://mediateca.inah.gob. $\underline{\mathrm{mx} / \text { islandora 74/islandora/object/libro\%3A425 }}$

Pérez Téllez, Iván (coord.) (2019). Indígenas Urbanos. Proyecto de Investigación Etnográfica de la Ciudad de México. Ciudad de México, México: Secretaría de Cultura, Gobierno de la Ciudad de México. Disponible en: https://redmifa.blog/2019/06/04/indigenas-urbanosproyecto-de-investigacion-etnografica-de-la-ciudad-de-mexico/ (Consultado el 4 de noviembre de 2020).

Rodríguez, Luisa (2019). “Los límites de la ciudadanía: marcos constitucionales y ordeamamientos espaciales para la población indígena en la ciudad de Querétaro México", Revista Antropologias del Sur, 6 (11), pp. 155-177. Disponible en: http://revistas.academia.cl/ index.php/rantros/article/view/1047/1312 (Consultado el 22 de febrero de 2021).

Ruiz Oscura, Karla, Ismael Pineda y Rubén Luna (2019). "Diversidad cultural en el norte de la Ciudad de México. La Delegación Gustavo A. Madero”, en Pérez Téllez, Iván (coord.). Indigenas Urbanos. Proyecto de investigación etnográfica de la Ciudad de México. Ciudad de México, México: Secretaría de Cultura, Gobierno de la Ciudad de México, pp. 44-65. Disponible en: https://redmifa.blog/2019/06/04/indigenas-urbanosproyecto-de-investigacion-etnografica-de-la-ciudad-de-mexico/ (Consultado el 4 de noviembre de 2020).

EntreDiversidades. Revista de Ciencias Sociales y Humanidades, Vol. 8, Núm. 2 (17), julio-diciembre 2021. Páginas: 6-29 ISSN-e: 2007-7610. https://doi.org/10.31644/ED.V8.N2.2021.A01 
Sánchez Gómez, Martha Judith (2014). "Reflexiones sobre la movilidad de la población indígena en México: desde la integración hasta la globalización", Amerique Latine Historie et Mémorie. Les Cahiers [en línea], Núm. 27. doi: https://doi.org/10.4000/alhim.4923 (Consultado el 19 de noviembre de 2020).

Vázquez Estrada, Alejandro y Prieto Hernández, Diego (eds.) (2013). Indios en la ciudad. Identidad, vida cotidiana e inclusión de la población indígena en la metrópoli queretana. México, D.F., México: Instituto Nacional de Antropología e Historia, Universidad Autónoma de Querétaro.

Yanes Rizo, Pablo (2010). "Indígenas urbanos y gestión en las ciudades: entre la interculturalidad y el racismo”, en Álvarez Enríquez, Lucia, Cristina Sánchez-Mejorada Fernández y Carlos San Juan Victoria (coords.). La gestión en las grandes ciudades. México, D.F., México: Universidad Nacional Autónoma de México, Universidad Autónoma Metropolitana Azcapotzalco, Instituto Nacional de Antropología e Historia, Juan Pablos Editor, pp. 341-375.

Zárate Hernández, Eduardo y Leal Sorcia, Olivia (2018). "Presentación dossier. Repensar la etnicidad en las metrópolis del siglo XXI". Andamios. Revista de investigación social [en línea], 15 (36), enero-abril, pp. 7-14. doi: http://dx.doi.org/10.29092/uacm.v15i36.599 (Consultado el 16 de octubre de 2020).

Zentella Chávez, Adriana Paola (2015). "Trayectorias y condiciones de vida de jóvenes mazatecos migrantes en la ciudad de México. Una perspectiva de género, de identidad y de clase social”. Crítica y Emancipación. Revista latinoamericana de ciencias sociales, Año VII (13), primer semestre, pp. 285-323. También disponible en: http://biblioteca.clacso.edu.ar/ clacso/clacso-crop/20131130121139/ZentellaArticuloF.pdf

\section{Entrevistas etnográficas}

Leal Sorcia, Olivia (2011). Entrevista colectiva. Mesa directiva de la Unión de Revistas, Libros y Publicaciones Atrasadas Vicente Guerrero Saldaña, A.C., Ciudad de México [comunicación personal]. 23 de junio de 2011. 